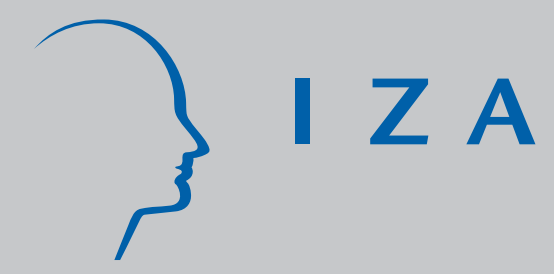

IZA DP No. 2043

Holdup in Oligopsonistic Labour Markets:

A New Role for the Minimum Wage

Leo Kaas

Paul Madden

March 2006 


\title{
Holdup in Oligopsonistic Labour Markets: A New Role for the Minimum Wage
}

\author{
Leo Kaas \\ University of Konstanz \\ and IZA Bonn \\ Paul Madden \\ University of Manchester
}

\section{Discussion Paper No. 2043 \\ March 2006}

\author{
IZA \\ P.O. Box 7240 \\ 53072 Bonn \\ Germany \\ Phone: +49-228-3894-0 \\ Fax: +49-228-3894-180 \\ Email: iza@iza.org
}

Any opinions expressed here are those of the author(s) and not those of the institute. Research disseminated by IZA may include views on policy, but the institute itself takes no institutional policy positions.

The Institute for the Study of Labor (IZA) in Bonn is a local and virtual international research center and a place of communication between science, politics and business. IZA is an independent nonprofit company supported by Deutsche Post World Net. The center is associated with the University of Bonn and offers a stimulating research environment through its research networks, research support, and visitors and doctoral programs. IZA engages in (i) original and internationally competitive research in all fields of labor economics, (ii) development of policy concepts, and (iii) dissemination of research results and concepts to the interested public.

IZA Discussion Papers often represent preliminary work and are circulated to encourage discussion. Citation of such a paper should account for its provisional character. A revised version may be available directly from the author. 
IZA Discussion Paper No. 2043

March 2006

\section{ABSTRACT}

\section{Holdup in Oligopsonistic Labour Markets: A New Role for the Minimum Wage}

We consider a labour market model of oligopsonistic wage competition and show that there is a holdup problem although workers do not have any bargaining power. When a firm invests more, it pays a higher wage in order to attract workers from competitors. Because workers participate in the returns on investment while only firms bear the costs, investment is inefficiently low. A binding minimum wage can achieve the first-best level of investment, both in the short run for a given number of firms and in the long run when the number of firms is endogenous.

JEL Classification: D43, J48

Keywords: holdup, investment, minimum wage

Corresponding author:

Leo Kaas

Department of Economics

University of Konstanz

Box D145

78457 Konstanz

Germany

Email: leo.kaas@uni-konstanz.de 


\section{Introduction}

The holdup problem of the labour market says that firms invest too little since workers can capture some of the return on investment after the costs of investment are sunk. Crucial for the result is that workers have some bargaining power and that workers and firms cannot sign binding wage contracts before investment decisions are made (see Grout (1984) and Malcomson (1999)). Moreover, more bargaining power of workers makes the problem worse by reducing firms' incentives to invest. On the other hand, when bargaining power of workers goes to zero, the holdup problem disappears.

In this paper, we show that a holdup problem also emerges when workers have no bargaining power at all, but when firms enter oligopsonistic wage competition after deciding about investment. The reason is that imperfect wage competition gives rise to rent sharing between workers and firms. When a firm invests more, it voluntarily wants to pay a higher wage in order to attract more workers from its competitors. Consequently, part of the returns of higher investment accrue to workers and not to the firms who bear all the investment costs. As a result, investment is inefficiently low.

Perhaps surprisingly, the holdup problem can be removed by the imposition of a binding minimum wage which alleviates the adverse effects of oligopsonistic wage competition. Whenever the minimum wage binds, firms optimally wish to pay a lower wage. By investing slightly more, a firm is thus not inclined to pay a higher wage but it keeps paying the minimum. Hence, additional investment does not translate into higher wages, so that all marginal gains from higher investment accrue to the firm who bears the investment cost. We show in fact that even the social optimum can be implemented by an appropriate choice of the minimum wage. This is true both in the short run when the number of firms is given, and in the long run when firms enter or exit the labour market.

Our model of an oligopsonistic labour market is a variation of the model of Bhaskar and To (1999). They use a Salop model of horizontal job differentiation to show positive welfare consequences of a binding minimum wage. In their paper, however, 
the beneficial effect of the minimum wage is based on the textbook monopsony argument: since employment is "too low" when firms enjoy labour market power, a minimum wage raises employment and thereby social welfare. In our paper, in contrast, there is no such employment effect: all workers are employed for any level of the minimum wage. Instead a minimum wage is helpful because of its positive impact on investment. ${ }^{1}$

Several contributions by Daron Acemoglu also find that binding minimum wages can be conducive for investment. Acemoglu (2001) shows how a wage floor changes the composition of jobs towards more capital-intensive, high-wage jobs. The result, however, works through the improved outside option of workers which makes it less attractive for firms to create low-wage jobs. Acemoglu (2003) shows how a minimum wage reduces ex-post rent sharing and leads to faster technology adoption for jobs with unskilled workers, thus providing an explanation of why the skill premium increased much less in Continental Europe than in the U.S. or in the UK over the past decades. Although his mechanism is very similar to ours, the ex-post rent sharing in Acemoglu's model is based on bargaining power on the side of workers. Cahuc and Michel (1996) and Acemoglu and Pischke (1999) argue that a minimum wage can induce workers or firms to invest more in education. In our model, in contrast, firms invest in better technology under the minimum wage.

The paper is organized as follows. After describing the model in Section 2, Section 3 derives the holdup problem under laissez faire. The beneficial effects of a minimum wage are discussed in Section 4 for an exogenous number of firms and in Section 5 with endogenous entry. Section 6 concludes. All proofs not contained in the text are in the Appendix.

\footnotetext{
${ }^{1}$ When the number of firms is endogenous, the minimum wage reduces entry which is also socially beneficial because entry is excessive under laissez faire. This effect is also present in the model of Bhaskar and To (1999).
} 


\section{The model}

The labour market is modeled by a Salop circle of unit circumference which is populated by a unit mass of uniformly distributed workers and $n \geq 2$ firms that are located symmetrically around the circle. For now the number $n$ is exogenously given, but in Section 5 we allow for free entry of firms. Workers pay quadratic transportation costs $t x^{2}$ to work for a firm located distance $x$ apart. These costs can be interpreted as geographical travel cost or as worker preferences over non-wage job characteristics. ${ }^{2}$

Firms operate linear technologies that produce output $y_{i}$ from $y_{i} / A_{i}$ units of labour which is the only input. Labour productivity $A_{i}$ depends on the amount of investment undertaken by firm $i$. Each firm has costless access to a basic technology with productivity $B$ which can be upgraded to a higher level $A_{i} \geq B$ at $\operatorname{cost}^{3} c \cdot\left(A_{i}-B\right)^{2}$. We model the strategic interaction by a two-stage game between profit-maximizing firms. At stage I, firms invest, deciding simultaneously about the level of technology $A_{i}, i=1, \ldots, n$. At stage II, firms offer wages $w_{i}, i=1, \ldots, n$, to workers. After wages have been announced, workers decide at what firm to work and production takes place. Note that we do not allow firms to wage discriminate between workers according to their locations. We also do not allow workers to renegotiate on the wage at offer. Thus there is no market power on the side of workers. This framework extends the model of Bhaskar and To $(1999,2003)$ by allowing firms to decide endogenously about technology. We simplify their model though by assuming that all workers are employed by some firm.

An equilibrium is a symmetric subgame perfect Nash equilibrium of this game. We restrict the model parameters in such a way that symmetric subgame perfect equilibria exist and have full employment of all workers:

$$
B>\frac{t}{2} \quad \text { and } \quad \frac{c t}{n}>\frac{1}{4} .
$$

\footnotetext{
${ }^{2}$ If transportation costs were linear instead of quadratic, payoff discontinuities may lead to non-existence of Nash equilibria in some of the subgames with asymmetric technology choices.

${ }^{3}$ Quadratic investment and transportation costs are convenient assumptions guaranteeing analytical solutions. As long as the relevant payoff functions are strictly concave, any other form of these cost functions would lead to similar results.
} 
As we show below, the first inequality implies that workers always prefer to work for some firm at equilibrium wages, regardless of technology. The second assumption guarantees that payoff functions are concave in technology choices. It also makes sure that all $n$ firms are active, invest the same amount and employ the same number of workers in the symmetric equilibrium. ${ }^{4}$ When we allow for free entry in Section 5, setup costs must be high enough so that the second condition holds for the endogenous number of entrants.

It is straightforward to obtain expressions for firms' profits depending on their strategies $\left(A_{i}, w_{i}\right), i=1, \ldots, n$. A worker located distance $x$ from firm $i$ and distance $1 / n-x$ from firm $i+1$ decides to work for $i$ iff $w_{i}-t x^{2} \geq w_{i+1}-t(1 / n-x)^{2}$ which is $x \leq 1 /(2 n)+\left(w_{i}-w_{i+1}\right) \cdot n /(2 t)$. When the wage differences between firms $i-1$, $i$ and $i+1$ are not too big, firm $i$ competes with its immediate neighbors so that $i$ 's employment is

$$
L_{i}\left(w_{i}, w_{i+1}, w_{i-1}\right)=\frac{1}{n}+\frac{n}{2 t}\left(2 w_{i}-w_{i+1}-w_{i-1}\right)
$$

and profit is

$$
\pi_{i}=\left(A_{i}-w_{i}\right) L_{i}\left(w_{i}, w_{i+1}, w_{i-1}\right)-c\left(A_{i}-B\right)^{2} .
$$

Consequently, the stage II best response problem of firm $i$ can be solved for the reaction function

$$
w_{i}=\frac{A_{i}-t / n^{2}}{2}+\frac{w_{i-1}+w_{i+1}}{4}
$$

\section{The holdup problem}

To characterize symmetric subgame perfect equilibria, it suffices to solve those stage II-subgames where firm 1 deviates with its investment decision $A_{1}$ from the one chosen by all other firms, $A_{i}=A, i=2, \ldots, n$. The following proposition shows the Nash equilibrium strategies of firm 1 and its two neighbors in these stage II subgames. The proof is in the Appendix.

\footnotetext{
${ }^{4}$ If the second condition in (1) is not satisfied, there may be equilibria where only a fraction of firms invest and all firms who do not invest are driven out of the market. There may also be multiple equilibria. A complete characterization of the equilibrium set for the case $n=2$ is available from the authors upon request.
} 
Proposition 1: Suppose that $A_{2}=A_{3}=\ldots=A_{n}=A$ and that

$$
-\frac{t}{n^{2}(1-\zeta)}<A_{1}-A<\frac{t}{n^{2}(2 \zeta-1)}
$$

where $\zeta \in(1 / \sqrt{3}, 2 / 3]$ is a constant which depends on $n$ only. Then the subgame Nash equilibrium strategies of firms 1,2 and $n$ are

$$
\begin{aligned}
w_{1} & =A-\frac{t}{n^{2}}+\zeta\left(A_{1}-A\right), \\
w_{2}=w_{n} & =A-\frac{t}{n^{2}}+(2 \zeta-1)\left(A_{1}-A\right),
\end{aligned}
$$

and employment at these firms is

$$
\begin{aligned}
L_{1} & =\frac{1}{n}+\frac{n}{t}(1-\zeta)\left(A_{1}-A\right), \\
L_{2}=L_{n} & =\frac{1}{n}+\frac{n}{t}(1-2 \zeta)\left(A_{1}-A\right) .
\end{aligned}
$$

Note that employment at firms 1,2 and $n$ is positive since $A_{1}-A$ lies in the range (4). Furthermore, $A_{i} \geq B$ implies that $w_{i} \geq B-t / n^{2}$ in any of these subgames. Thus there will be full employment of all workers: even those workers who are located diametrically opposed of some firm $i$ are willing to work for $i$ since $w_{i}-t(1 / 2)^{2} \geq 0$ because of $(1)$ and $n \geq 2$.

The proposition shows that workers at firm 1 and at its neighbors benefit from higher investment by firm 1: when $A_{1}>A$, wages at firm 1 and at its neighbors are increasing. ${ }^{5}$ This is precisely the reason why firms underinvest under oligopsonistic competition. When firm 1 invests more, it also raises its wage in order to attract more workers. Its neighbors follow suit because their reaction function (3) is increasing in neighboring wages, and this further drives firm 1's wage up. As a result, part of the gains from investment accrue to workers, but investment costs are only borne by firms.

To show this formally, let us derive the equilibrium investment level. In a symmetric equilibrium $A_{1}=\ldots=A_{n}=A$ we must make sure that firm 1 does not want to deviate from $A$. Since Proposition 1 characterizes stage II subgames for nearby deviations from symmetric strategies, it is straightforward to characterize the condition

\footnotetext{
${ }^{5}$ In fact, wages at all $n$ firms are increasing in $A_{1}$, as shown in the proof of Proposition 1.
} 
for a local best response. Deviations below $A-t /\left(n^{2}(1-\zeta)\right)$ lead to $L_{1}=0$ and are clearly not profitable for firm 1 . Deviations above $A+t /\left(n^{2}(2 \zeta-1)\right)$ lead to $L_{2}=L_{n}=0$ so that firm 1 starts competing with firms 3 and $n-2$. In the proof of Theorem 1 we show that such deviations are never profitable for firm 1 .

When $A_{1}$ is in the range (4), firm 1's profit is

$$
\begin{aligned}
\pi_{1}\left(A_{1}, A\right) & =\left(A_{1}-w_{1}\right) L_{1}-c\left(A_{1}-B\right)^{2} \\
& =\frac{n}{t}\left(\frac{t}{n^{2}}+(1-\zeta)\left(A_{1}-A\right)\right)^{2}-c\left(A_{1}-B\right)^{2} .
\end{aligned}
$$

Assumption (1) implies that $\pi_{1}$ is strictly concave in $A_{1}$. It is maximized at

$$
A_{1}=R(A) \equiv \frac{\frac{t}{n}(1-\zeta)+c t B-(1-\zeta)^{2} A n}{c t-(1-\zeta)^{2} n} .
$$

The best response function $R$ is downward-sloping (with slope $>-1$, again under (1)). Thus, there exists a (stable) Nash equilibrium

$$
A^{*}=B+\frac{1-\zeta}{c n} .
$$

It is now straightforward to show that there is too little investment in the decentralized equilibrium. When all $n$ firms choose technology $A$, social welfare (i.e. total output minus costs of transportation and investment) is

$$
\begin{aligned}
S_{n}(A) & =n\left(2 \int_{0}^{1 /(2 n)} A-t x^{2} d x-c(A-B)^{2}\right) \\
& =A-\frac{t}{12 n^{2}}-c n(A-B)^{2},
\end{aligned}
$$

which is maximal at

$$
A^{S}=B+\frac{1}{2 c n}
$$

Because of $\zeta>1 / \sqrt{3}>1 / 2$, investment in the decentralized equilibrium is below the socially optimal level. This is the holdup problem in this model: although workers do not have any bargaining power, some of the rents of investment accrue to workers because of oligopsonistic wage competition between firms.

Theorem 1: Suppose that assumption (1) holds. Then there exists a unique symmetric subgame perfect Nash equilibrium in which all firms invest $A^{*}$, pay the wage $w^{*}=A^{*}-t / n^{2}$, and make profits $\pi^{*}=\frac{t}{n^{3}}-c\left(\frac{1-\zeta}{c n}\right)^{2}$. Investment is below the socially optimal level $A^{S}$. 


\section{The beneficial effect of a minimum wage}

Consider now the impact of a minimum wage $\bar{w}$ which is announced before firms make investment decisions. That is, prior to stage I, firms respect that stage II wage strategies are bounded below by $w_{i} \geq \bar{w}$. Paralleling Proposition 1, Proposition 2 characterizes the subgame equilibrium at stage II when one firm deviates locally from a symmetric configuration at stage I.

Proposition 2: Suppose that $A_{2}=A_{3}=\ldots=A_{n}=A$ and that $A_{1}$ in the range (4). Then, the stage II subgame Nash equilibrium is as follows.

(a) Suppose that $\bar{w} \leq A-t / n^{2}$. If $A_{1}>\hat{A} \equiv\left(\bar{w}+t / n^{2}-(1-\zeta) A\right) / \zeta(\leq A)$, the stage II equilibrium is as the laissez-faire equilibrium of Proposition 1. If $A_{1} \leq \hat{A}$, the minimum wage binds for firm 1 , and the stage II equilibrium is as in Proposition 1 with $\hat{A}$ replacing $A_{1}$ in the expressions for $w_{i}$ and $L_{i}$, $i=1,2, n$. In this case, the minimum wage does not bind for all firms $i>1$ when $\bar{w}<A-t / n^{2}$ and it binds for all firms when $\bar{w}=A-t / n^{2}$.

(b) Suppose that $\bar{w}>A-t / n^{2}$. If $A_{1} \leq \bar{w}+t / n^{2}$, the minimum wage binds for all firms at stage II, so that employment levels are $L_{i}=1 / n$ for all $i=1, \ldots, n$. If $A_{1}>\bar{w}+t / n^{2}$, firm 1 pays a wage above the minimum wage and, for $A_{1}$ big enough, so do its neighbors.

Proof: Appendix.

Part (b) of the Proposition shows that a marginal investment increase by firm 1 does not translate into higher wages when the minimum wage is binding. Hence, all marginal returns on investment accrue to firm 1, in contrast to the laissez-faire framework of the previous section. This is the reason why a minimum wage induces firms to invest more.

To analyze how the minimum wage affects investment, consider the laissez-faire equilibrium $A^{*}, w^{*}=A^{*}-t / n^{2}$ from Theorem 1 , and suppose first that the minimum wage is below the laissez-faire wage, $\bar{w} \leq w^{*}$. Then no firm wants to deviate with its technology choice from $A^{*}$ : any deviation in the range $A_{1} \geq \hat{A}$ (see Proposition 
2(a)) cannot be profitable since wages at stage II are as under laissez faire and so the proof of Theorem 1 applies analogously. Firm 1 also does not want to deviate below $\hat{A}$ : Proposition 2 shows that then $w_{1}=\bar{w}$ and $L_{1}=\hat{L}_{1} \equiv 1 / n+n(1-\zeta)\left(\hat{A}-A^{*}\right) / t$ are independent of $A_{1}$ so that firm 1's profit is

$$
\hat{\pi}_{1}\left(A_{1}\right) \equiv\left(A_{1}-\bar{w}\right) \hat{L}_{1}-c\left(A_{1}-B\right)^{2},
$$

a concave function of $A_{1}$ with $\hat{\pi}_{1}^{\prime}(\hat{A})=\hat{L}_{1}-2 c(\hat{A}-B)$. On the other hand, firm 1's profit function for $A_{1} \geq \hat{A}$ is $\pi_{1}\left(A_{1}, A^{*}\right)$ as defined in (5) whose slope at $A_{1}=\hat{A}$ is $d \pi_{1} /\left(d A_{1}\right)\left(\hat{A}, A^{*}\right)=2(1-\zeta) \hat{L}_{1}-2 c(\hat{A}-B)$ which is smaller than $\hat{\pi}_{1}^{\prime}(\hat{A})$ because $\zeta>1 / 2$. This shows that firm 1's profit is concave in $A_{1} \leq A^{*}$ which proves that downward deviations do not pay off either. Hence, the laissez-faire equilibrium remains an equilibrium for any minimum wage $\bar{w} \leq w^{*}$.

When $\bar{w}>w^{*}$, however, the laissez-faire equilibrium is replaced by an equilibrium with higher investment and firms paying the minimum wage. Provided that $\bar{w}$ is not too big, firms invest exactly $A=\bar{w}+t / n^{2}$, so that stage II wage competition leads all firms to set the minimum wage (Proposition 2(a)). Indeed, suppose that firms $i \geq 2$ invest $A=\bar{w}+t / n^{2}$. Then, when $A_{1} \geq A$, Proposition 2(a) says that firm 1 gets laissez-faire profit $\pi_{1}\left(A_{1}, A\right)$ as shown in equation (5), and since $\bar{w}>w^{*}$, we have

$$
\begin{aligned}
\frac{d \pi_{1}}{d A_{1}}(A, A) & =\frac{2}{n}(1-\zeta)-2 c\left(\bar{w}+\frac{t}{n^{2}}-B\right) \\
& <\frac{2}{n}(1-\zeta)-2 c\left(\frac{1}{c n}(1-\zeta)\right)=0 .
\end{aligned}
$$

Hence, upward technology deviations are not profitable for firm 1 . When firm 1 chooses $A_{1}<A$, all firms continue to pay $\bar{w}$ (Proposition 2(a) again), firm 1's employment is $L_{1}=1 / n$, and its profit is

$$
\bar{\pi}_{1}\left(A_{1}\right) \equiv\left(A_{1}-\bar{w}\right) \frac{1}{n}-c\left(A_{1}-B\right)^{2} .
$$

Thus, downward deviations from $A=\bar{w}+t / n^{2}$ are not profitable provided that

$$
\bar{\pi}^{\prime}(A)=\frac{1}{n}-2 c\left(\bar{w}+\frac{t}{n^{2}}-B\right) \geq 0,
$$

which is the case whenever

$$
\bar{w} \leq B+\frac{1}{2 c n}-\frac{t}{n^{2}}=w^{S} \equiv A^{S}-\frac{t}{n^{2}}
$$


Therefore, for any minimum wage $\bar{w} \in\left[w^{*}, w^{S}\right]$, the technology choice $A=\bar{w}+t / n^{2}$ is the symmetric equilibrium of this game. In particular, the social optimum is implemented as a decentralized equilibrium for the minimum wage $\bar{w}=w^{S}$.

When $\bar{w}>w^{S}$, the social optimum $A_{i}=A^{S}$ continues to be the unique equilibrium, as long as profits are non-negative. In this case, firm 1's profit for small deviations from $A=A^{S}$ is given by (8) since the minimum wage binds on all firms. Because the local maximum is attained at $A_{1}=A^{S}, A^{S}$ is a local best response to $A_{i}=A^{S}$, $i \geq 2$. Only when firm 1 raises $A_{1}$ far above $A^{S}$ the minimum wage would not bind on firm 1 (and possibly not on other firms for large enough $A_{1}$ ). But such deviations are not profitable as well. ${ }^{6}$ Profits at the socially optimal technology level are non-negative if, and only if,

$$
\bar{w} \leq \hat{w} \equiv B+\frac{1}{4 c n} .
$$

Note that assumption (1) implies that $\hat{w}>w^{S}$. When $\bar{w}>\hat{w}$ there is no equilibrium in which all $n$ firms operate with non-negative profits so that some firms must leave the market. Such issues are discussed in the following section. Hence, we have established

Theorem 2: Suppose that a minimum wage $\bar{w}$ is imposed prior to firms' investment decisions at stage I. Then the unique symmetric equilibrium is as follows.

(a) If $\bar{w} \leq w^{*}$, the equilibrium is the laissez-faire equilibrium of Theorem 1 .

(b) If $w^{*}<\bar{w}<w^{S}$, the equilibrium is $A_{i}=\bar{w}+t / n^{2}>A^{*}$ and $w_{i}=\bar{w}, i=1, \ldots, n$, with higher social welfare than under laissez faire.

(c) If $w^{S} \leq \bar{w} \leq \hat{w}$, the social optimum $A_{i}=A^{S}, w_{i}=\bar{w}, i=1, \ldots, n$ is an equilibrium.

(d) If $\hat{w}<\bar{w}$, there is no equilibrium with $n$ active firms.

\footnotetext{
${ }^{6}$ Formally, when $A_{1}>\bar{w}+t / n^{2}>A^{S}$, the minimum wage does not bind for 1 but binds for its neighbors (when $A_{1}$ is not too big). Firm 1 pays then $w_{1}=\left(A_{1}+\bar{w}-t / n^{2}\right) / 2>\bar{w}$ and makes profit $\pi_{1}\left(A_{1}\right)=\left(A_{1}-\bar{w}+t / n^{2}\right)^{2} \cdot n /(4 t)-c\left(A_{1}-B\right)^{2}$. Then $\pi_{1}^{\prime}\left(A_{1}\right)=\left(A_{1}-\bar{w}+t / n^{2}\right) \cdot n /(2 t)-2 c\left(A_{1}-B\right)<$ $\left(A^{S}-\bar{w}-t / n^{2}\right) \cdot n /(2 t)<0$. Thus such deviations are not profitable.
} 


\section{Endogenous entry}

Suppose that firms incur fixed costs $F>0$ representing all expenses that are independent of the scale of production, such as rent, insurance etc. The strategic interaction between firms is augmented by a decision whether to enter the market or not, prior to the technology decisions. Thus, at stage 0, a large number of firms decide simultaneously about entry. Entrant firms are assumed to locate symmetrically around the circle. It is well known that free entry in the Salop model leads to an excessive number of firms due to the so-called business-stealing effect (see Mankiw and Whinston (1986)): an individual firm ignores the negative impact of its own entry on the output of competitors. To show that this is also the case in our model with endogenous technology choice, compare the number of firms under free entry with the socially optimal number of firms. The proof of Proposition 1 shows that the constant $\zeta$ is a declining function of the number of firms, so we denote it by $\zeta(n)$. The equilibrium number of firms under laissez-faire solves

$$
\pi^{*}(n)=\frac{t}{n^{3}}-c\left(\frac{1-\zeta(n)}{c n}\right)^{2}=F
$$

$\pi^{*}$ is a declining function whenever it is positive. Let $n^{*}$ denote the equilibrium number of firms, assuming that $F$ is big enough so that (1) holds for $n^{*}$.

The socially optimal number of firms, denoted $n^{S}$, is found from maximizing $S_{n}(A)-$ $n F$ with respect to $n$ and $A$ which amounts to solving the first-order condition

$$
G(n) \equiv \frac{t}{6 n^{3}}-\frac{1}{4 c n^{2}}=F
$$

Because $\pi^{*}(n)>G(n)$ for all $n$, and since both functions are downward sloping (whenever they are positive), $n^{*}>n^{S}$. Hence, the business-stealing effect is also present in our model with endogenous technology choice.

Under free entry, a minimum wage has beneficial effects for two reasons. The first effect is the investment effect of the previous section: as wage competition is alleviated, the firms' returns on investment are higher which stimulates investment. Secondly, there is a beneficial entry effect: profits are falling and fewer firms enter the market. Note that the second effect also indirectly spurs investment: when 
fewer firms enter the market, each firm serves a larger market share and invests more (formally, Theorem 2 shows that the equilibrium $A$ is declining in $n$ ).

One can also show that the first-best level of $n$ and $A$ can be implemented by an appropriate choice of the minimum wage. Let $A^{*}(n)$ denote the equilibrium investment level of Theorem 1 under laissez-faire, and let $A^{*} \equiv A^{*}\left(n^{*}\right)$ denote investment under free entry. Similarly, denote by $A^{S}(n)$ the socially-optimal investment level for $n$ given firms, and let $A^{S}\left(n^{S}\right)$ be the optimal investment level when the number of firms is socially optimal. We have shown before that $A^{*}(n)<A^{S}(n)$ for all $n$, and that both functions are declining in $n$. Thus, $A^{*}=A^{*}\left(n^{*}\right)<A^{*}\left(n^{S}\right)<A^{S}\left(n^{S}\right)=A^{S}$ (see Figure 1). When a binding minimum wage is increased, firms invest more but profits are declining and so fewer firms enter the market. In the $(n, A)$-diagram of Figure 1, the decentralized equilibrium moves away from the laissez-faire $\left(n^{*}, A^{*}\right)$ towards the north-west. At some point, the minimum wage becomes larger than $w^{S}(n)=A^{S}(n)-t / n^{2}$ in which case the $n$ active firms invest the amount $A^{S}(n)$ (see Theorem 2(c)). Further increases of the minimum wage reduce the number of firms further and raise investment according to $A^{S}(n)$. Figure 1 shows that firms start investing $A^{S}(n)$ when $\hat{n}$ firms enter the market, and that $\hat{n}$ is bigger than the socially optimal number of firms $n^{S}$. A proof of this result is in the Appendix. Therefore, there exists a level of the minimum wage above $w^{S}(\hat{n})$ which implements the social optimum $\left(n^{S}, A^{S}\right)$. Further increases of the minimum wage lead to an inefficiently low number of active firms who invest more and more until, at some point, all firms leave the market.

Theorem 3: Under free-entry, an increase of the minimum wage reduces the number of firms and raises investment. Social welfare increases for moderate levels of the minimum wage and it falls for higher levels. There exists a minimum wage implementing the social optimum $\left(n^{S}, A^{S}\right)$ as a decentralized equilibrium. 


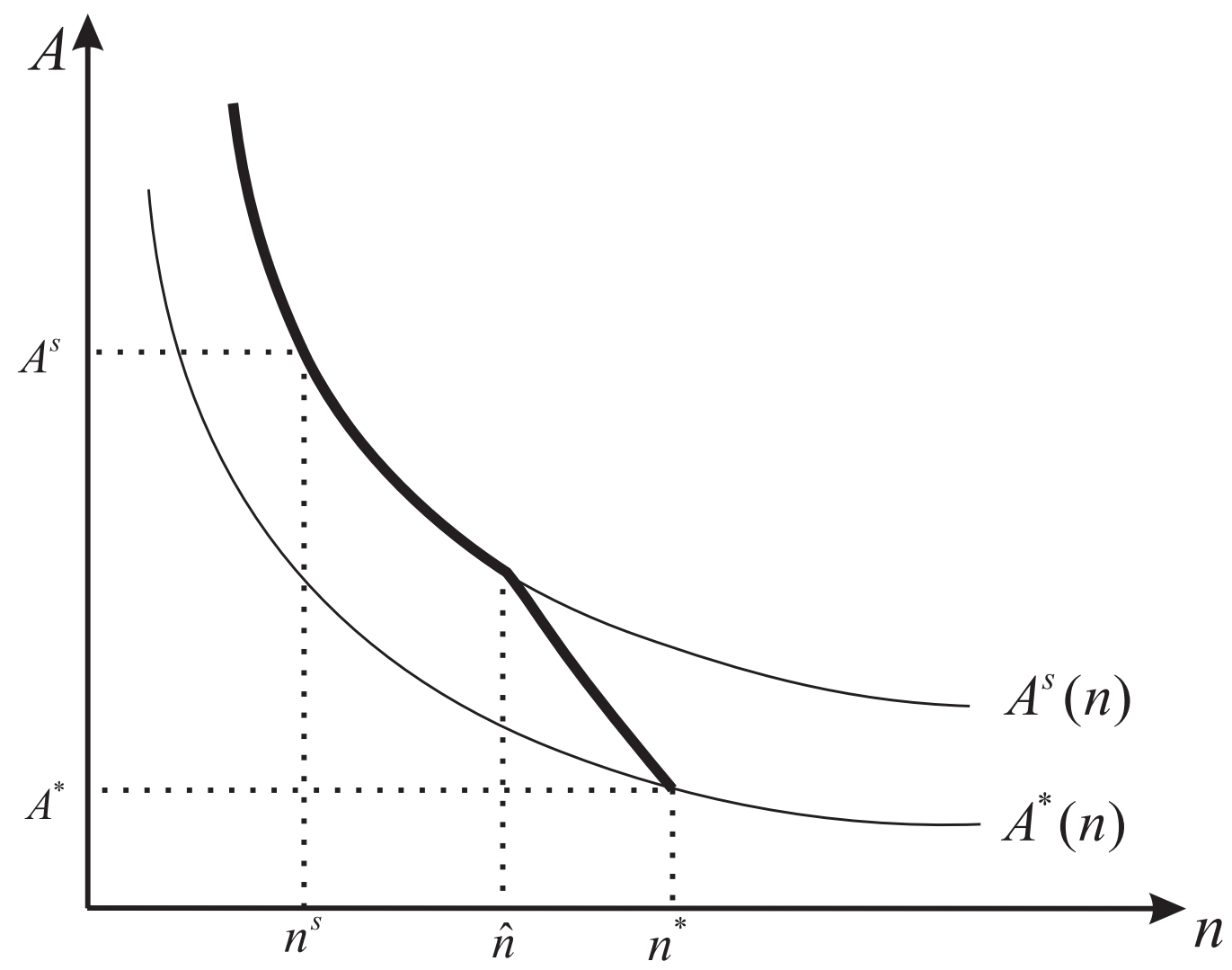

Figure 1: The bold curve shows market size and investment for different levels of the minimum wage.

\section{Conclusions}

The paper has established a beneficial effect of a minimum wage policy which is different from the well-known positive employment effects in monopsonistic or oligopsonistic labour markets. In an economy with full employment of all workers and market power on the side of firms, there is too little investment because workers benefit from better technology via higher wages, whereas investment costs are only borne by firms. A binding minimum entails that all marginal returns from investment accrue to firms which induces them to invest more.

There may be other dimensions along which minimum wages have positive welfare effects. This paper has abstracted from issues of firm location by assuming that firms 
always locate symmetrically around the circle. In a related paper (Kaas and Madden (2006)) we show within a two-firm Hotelling model that there is too much differentiation of non-wage job characteristics under laissez-faire. A moderate minimum wage turns out to be welfare-improving by reducing horizontal job differentiation.

\section{References}

Acemoglu, D. (2001): "Good Jobs versus Bad Jobs," Journal of Labor Economics, $19,1-22$.

(2003): "Cross-Country Inequality Trends," The Economic Journal, 113, $121-149$.

Acemoglu, D., And J. Pischke (1999): "Beyond Becker: Training in Imperfect Labour Markets," The Economic Journal, 109, 112-142.

Bhaskar, V., And T. To (1999): "Minimum Wages for Ronald McDonald Monopsonies: A Theory of Monopsonistic Competition," The Economic Journal, 109, 190-203.

- (2003): "Oligopsony and the Distribution of Wages," European Economic Review, 47, 371-399.

Cahuc, P., And J. Michel (1996): "Minimum wage, unemployment and growth," European Economic Review, 40, 1463-1482.

Grout, P. (1984): "Investment and Wages in the Absence of Binding Contracts: a Nash Bargaining Approach," Econometrica, 52, 449-460.

KaAs, L., And P. Madden (2006): "Hotelling Duopsony with Asymmetric Firm Efficiency," Mimeo, University of Manchester.

Malcomson, J. (1999): "Individual Employment Contracts," in Handbook of Labor Economics, ed. by O. Ashenfelter, and D. Card, vol. 3, chap. 35. North-Holland, Amsterdam. 
Mankiw, N., And M. Whinston (1986): "Free Entry and Social Inefficiency," RAND Journal of Economics, 17, 48-58.

Mas-Colell, A., M. D. Whinston, and J. R. Green (1995): Microeconomic Theory. Oxford University Press, Oxford.

\section{Appendix}

\section{Proof of Proposition 1:}

If firm 1 deviates with $A_{1}$ from $A_{2}=\ldots=A_{n}=A$ a little, it competes with its immediate neighbors $i=2, n$, and its stage II best response (3) to the symmetric wages $w_{2}=w_{n}$ is $^{7}$

$$
w_{1}=k_{1}+\frac{w_{2}}{2}
$$

where $k_{1} \equiv\left(A_{1}-t / n^{2}\right) / 2$. Because firm 2 competes with $i=1,3$, its best response is

$$
w_{2}=k+\frac{w_{1}+w_{3}}{4}
$$

where $k \equiv\left(A-t / n^{2}\right) / 2$. Similarly, the best response of all firms $i=2, \ldots, m$, where $m \leq n / 2$, is

$$
w_{i}=k+\frac{w_{i-1}+w_{i+1}}{4}, i=2, \ldots, m \text {. }
$$

Suppose that $n$ is even so that $n=2 m$. Then, the best response for all firms $i=2, \ldots, m$ is given by (10), and the best response problem of firm $m+1$ is

$$
w_{m+1}=k+\frac{w_{m}}{2}
$$

because $w_{m}=w_{m+2}$. Therefore, the stage II Nash equilibrium is a solution $\left(w_{i}\right)_{i=1}^{n}$ that satisfies $w_{i}=w_{n+2-i}, i=2, \ldots, m$, and the best-response conditions (9), (10) and (11). With $\lambda_{i} \equiv w_{i}-2 k$, one needs to find a solution to the difference equation

$$
\lambda_{i+1}=4 \lambda_{i}-\lambda_{i-1}, i=2, \ldots, m,
$$

\footnotetext{
${ }^{7}$ As we show in the proof of Theorem 1 below, the profit function of firm $i$ is strictly concave in $w_{i}$ in the whole domain $w_{i} \in\left[0, A_{i}\right]$. Therefore equation (3) describes indeed the best response of firm $i$ provided that employment levels at firms $i-1, i$ and $i+1$ are strictly positive. Below we show that this is the case when $A_{1}$ lies in the range (4).
} 
satisfying the boundary conditions

$$
\begin{gathered}
\lambda_{1}=k_{1}-k+\lambda_{2} / 2, \\
\lambda_{m+1}=\lambda_{m} / 2 .
\end{gathered}
$$

The general solution of (12) is $\lambda_{i}=\alpha \mu_{1}^{i-1}+\beta \mu_{2}^{i-1}$, where $\mu_{1}=2+\sqrt{3}$ and $\mu_{2}=$ $2-\sqrt{3}$. The two boundary conditions (13) and (14) yield

$$
\begin{aligned}
\alpha & =\beta\left(\frac{\mu_{2}}{\mu_{1}}\right)^{m} \\
\beta & =\frac{2\left(k_{1}-k\right) / \sqrt{3}}{1-\left(\mu_{2} / \mu_{1}\right)^{m}} .
\end{aligned}
$$

Using this shows that

$$
w_{1}=\lambda_{1}+2 k=\alpha+\beta+2 k=A-t / n^{2}+\zeta(n)\left(A_{1}-A\right)
$$

where

$$
\zeta(n) \equiv \frac{1}{\sqrt{3}} \cdot \frac{(2+\sqrt{3})^{n / 2}+(2-\sqrt{3})^{n / 2}}{(2+\sqrt{3})^{n / 2}-(2-\sqrt{3})^{n / 2}} .
$$

Thus, $\zeta(2)=2 / 3$ and $\zeta(\infty)=1 / \sqrt{3}$. Moreover, $\zeta$ is declining in $n$, and a similar consideration for odd values of $n$ confirms that $\zeta(n) \in\left[\sqrt{3}^{-1}, 2 / 3\right]$ for all $n$. The stage II equilibrium wage paid by the neighbors of firm 1 is

$$
w_{2}=\lambda_{2}+2 k=2 \lambda_{1}-2\left(k_{1}-k\right)+2 k=A-t / n^{2}+(2 \zeta(n)-1)\left(A_{1}-A\right) .
$$

The expressions for employment at firms 1,2 and $n$ follow then from (2) which are all positive, provided that $A_{1}$ is in the range (4). It can also be shown that then all other firms' employment levels are positive. Thus, the established solution is indeed a Nash equilibrium.

\section{Proof of Theorem 1:}

It remains to prove that firm 1 does not want to deviate above $\bar{A}_{1} \equiv A^{*}+t /\left(n^{2}(2 \zeta-\right.$ 1)) in order to capture its immediate neighbors' markets (any further upward deviations to capture an even larger market are not profitable for similar reasons). First of all, note that employment of firm 1 can be written as $L_{1}=\max \left(0, L_{1}^{-}+L_{1}^{+}\right)$ where

$$
L_{1}^{+}=\min \left(\frac{1}{2 n}+\frac{n}{2 t}\left(w_{1}-w_{2}\right), \frac{1}{n}+\frac{n}{4 t}\left(w_{1}-w_{3}\right), \frac{3}{2 n}+\frac{n}{6 t}\left(w_{1}-w_{3}\right), \ldots\right),
$$




$$
L_{1}^{-}=\min \left(\frac{1}{2 n}+\frac{n}{2 t}\left(w_{1}-w_{n}\right), \frac{1}{n}+\frac{n}{4 t}\left(w_{1}-w_{n-1}\right), \frac{3}{2 n}+\frac{n}{6 t}\left(w_{1}-w_{n-2}\right), \ldots\right) .
$$

These equations reflect the observation that employment of some low wage firms next to firm 1 may be zero in which case firm 1 competes with other firms located further away. The equations show that $L_{1}$ is strictly increasing, continuous and concave in $w_{1}$. Therefore, firm 1's profit function $\pi_{1}=\left(A_{1}-w_{1}\right) L_{1}$ is strictly concave and continuous in all arguments. This implies that there exists a continuous best response function $w_{1}=R_{1}\left(w_{2}, \ldots, w_{n}\right)$. Moreover, $R_{1}$ is non-decreasing in each argument (just as (3) is non-decreasing in $w_{2}$ and $w_{n}$ ). A Nash equilibrium of any subgame after technology choices $\left(A_{i}\right)_{i=1}^{n}$ is a fixed point of the collection of best response functions $R=\left(R_{1}, \ldots, R_{n}\right): \prod_{i}\left[0, A_{i}\right] \rightarrow \prod_{i}\left[0, A_{i}\right]$. Because each $R_{i}$ is non-decreasing, a fixed point exists because of Tarsky's fixed point theorem (see Theorem M.I.3 in Mas-Colell, Whinston, and Green (1995)). Hence any stage II subgame has a pure strategy equilibrium.

Suppose now that $A_{1}>\bar{A}_{1}$ so that $L_{2}=L_{n}=0$ and firm 1 competes with 3 and $n-1$. Given that these firms set wages $w_{3}=w_{n-1}$, firm 1's employment is

$$
L_{1}=\frac{2}{n}+\frac{n}{2 t}\left(w_{1}-w_{3}\right)
$$

and so its profit is

$$
\pi_{1}\left(A_{1}, w_{1}, w_{3}\right)=\left(A_{1}-w_{1}\right)\left(\frac{2}{n}+\frac{n}{2 t}\left(w_{1}-w_{3}\right)\right)-c\left(A_{1}-B\right)^{2} .
$$

Firm 1's best response at stage II is

$$
w_{1}\left(A_{1}, w_{3}\right)=\frac{A_{1}+w_{3}-4 t / n^{2}}{2}
$$

which gives

$$
\hat{\pi}_{1}\left(A_{1}, w_{3}\right) \equiv \pi_{1}\left(A_{1}, w_{1}\left(A_{1}, w_{3}\right), w_{3}\right)=\frac{n}{8 t}\left(A_{1}-w_{3}+\frac{4 t}{n^{2}}\right)^{2}-c\left(A_{1}-B\right)^{2}
$$

a decreasing function of $w_{3}$. In any subgame equilibrium at stage II in which 1 and 3 compete, firm 3's wage $w_{3}\left(A_{1}\right)$ is increasing in $A_{1}$. The optimal technology choice of firm 1 , denoted $\hat{A}_{1} \geq \bar{A}_{1}$ solves

$$
\hat{\pi}_{1 A}^{\prime}\left(\hat{A}_{1}, w_{3}\left(\hat{A}_{1}\right)\right)+\hat{\pi}_{1 w}^{\prime}\left(\hat{A}_{1}, w_{3}\left(\hat{A}_{1}\right)\right) w_{3}^{\prime}\left(\hat{A}_{1}\right)=0
$$


Because of $w_{3}^{\prime}>0$ and $\hat{\pi}_{1 w}^{\prime}<0$

$$
\hat{\pi}_{1 A}^{\prime}\left(\hat{A}_{1}, w_{3}\left(\hat{A}_{1}\right)\right)>0
$$

Further, because $\hat{\pi}_{1 A}^{\prime}$ is decreasing in the second argument and since $w_{3}\left(\hat{A}_{1}\right)>w^{*}=$ $A^{*}-t / n^{2}$, we also have

$$
\hat{\pi}_{1 A}^{\prime}\left(\hat{A}_{1}, w^{*}\right)>0
$$

Assumption (1) implies that $\hat{\pi}_{1}$ is concave in $A_{1}$. The unique maximizer of $\hat{\pi}_{1}\left(., w^{*}\right)$, denoted $\tilde{A}_{1}$, must be bigger than $\hat{A}_{1}$ because of (17). If we can show that $\tilde{A}_{1}$ is smaller than $\bar{A}_{1}$ we obtain a contradiction because $\hat{A}_{1}<\tilde{A}_{1}<\bar{A}_{1} \leq \hat{A}_{1}$. Maximization of $\hat{\pi}_{1}\left(., w^{*}\right)$ and using $w^{*}=B+(1-\zeta) /(c n)-t / n^{2}$ yields

$$
\tilde{A}_{1}=B+\frac{1}{8 c t-1}\left(\frac{5 t}{n}-\frac{1-\zeta}{c}\right) .
$$

The condition $\tilde{A}_{1}<\bar{A}_{1}=B+(1-\zeta) /(c n)+t /\left(n^{2}(2 \zeta-1)\right)$ turns out to be equivalent to

$$
4 \frac{c t}{n}>2+8 \zeta^{2}-7 \zeta
$$

The right-hand side attains the maximum of $8 / 9$ at $\zeta=2 / 3$ so that (18) holds if $c t / n>2 / 9$, another implication of assumption (1).

\section{Proof of Proposition 2:}

Note first that each firm $i$ 's profit functions is strictly concave in $w_{i} \geq \bar{w}$ so that a local best response is a global best response. On (a), suppose first that $A_{1}>\hat{A}$. Then the proof is as in Proposition 1 because all wages are above the minimum wage and no firm can increase its profit by reducing its wage to the minimum. Now consider $A_{1} \leq \hat{A}$. When $A=\bar{w}+t / n^{2}$ so that $\hat{A}=A$, all firms pay the minimum wage: (3) shows that $\bar{w}$ is a best response for any $i$ to both neighbors setting $\bar{w}$. When $A>\bar{w}+t / n^{2}$ and $A_{1}=\hat{A}<A$, firm 1 pays the minimum wage and all other firms pay higher wages: Proposition 1 shows that 1's immediate neighbors 2 and $n$ pay higher wages, and the same is true for all other firms which follows directly from the solution in the proof of Proposition 1 . When $A_{1}<\hat{A}$, nothing changes relative to $A_{1}=\hat{A}$ since firm 1 keeps paying the minimum wage and all other firms are not affected by the lower investment of firm 1 . 
On (b), suppose first that $A_{1} \leq \bar{w}+t / n^{2}$. Then (3) shows that any firm $i=1, \ldots, n$ would optimally wish to pay a wage below the minimum wage when its two neighbors pay the minimum. Since $i$ 's payoff is concave in $w_{i}, w_{i}=\bar{w}$ is thus a best response to $w_{i-1}=w_{i+1}=\bar{w}$, and so all firms pay the minimum wage in the stage II Nash equilibrium. When $A_{1}>\bar{w}+t / n^{2}$, in contrast, firm 1's best response to $w_{2}=w_{n}=\bar{w}$ exceeds $\bar{w}$. Then, in the stage II Nash equilibrium firm 1 (and potentially some of its neighbors) pay wages above the minimum wage.

\section{Proof of Theorem 3:}

Suppose that $n$ firms enter the market at stage 0. Each firm's profit depends on the level of the minimum wage. According to Theorem 2, firms can be in one of three situations.

1. If $\bar{w}<w^{*}(n)=B+\frac{1-\zeta(n)}{c n}-\frac{t}{n^{2}}$, the minimum wage does not bind, firms invest $A^{*}(n)$, and profits are

$$
\pi^{*}(n)=\frac{t}{n^{3}}-c\left(\frac{1-\zeta(n)}{c n}\right)^{2} .
$$

2. If $w^{*}(n) \leq \bar{w}<w^{S}(n)=B+\frac{1}{2 c n}-\frac{t}{n^{2}}$, the minimum wage binds, firms invest more than $A^{*}(n)$ but less than $A^{S}(n)$, and profits are

$$
\pi^{B}(n)=\frac{t}{n^{3}}-c\left(\bar{w}+\frac{t}{n^{2}}-B\right)^{2} .
$$

3. If $w^{S}(n)<\bar{w}$, the minimum wage binds, firms invest $A^{S}(n)$, and profits are

$$
\pi^{S}(n)=\left(B+\frac{1}{2 c n}-\bar{w}\right) \frac{1}{n}-c\left(\frac{1}{2 c n}\right)^{2} .
$$

When $\bar{w}$ is increased above $w^{*}=w^{*}\left(n^{*}\right)$, less than $n^{*}$ firms enter the market who all invest more than $A^{*}(n)$. At some point, firms start investing $A^{S}(n)$. This happens when the number of firms $\hat{n}$ satisfies

$$
\pi^{B}(\hat{n})=\pi^{S}(\hat{n})=F
$$

The corresponding minimum wage is $w^{S}(\hat{n})=B+\frac{1}{2 c \hat{n}}-\frac{t}{\hat{n}^{2}}$. Using (19),

$$
\pi^{S}(\hat{n})=\frac{t}{\hat{n}^{3}}-\frac{1}{4 c \hat{n}^{2}}>G(\hat{n})
$$


where $G$ is defined in the text. This implies that $\hat{n}>n^{S}$ because $G$ is downwardsloping. Therefore, when the minimum wage is increased further, the number of firms falls to the first-best level $n^{S}$ who invest the first-best $A^{S}=A^{S}\left(n^{S}\right)$. The corresponding level of the minimum wage can be computed as follows. Using (19), the free-entry condition $\pi^{S}\left(n^{S}\right)=F$ can be solved for the socially optimal minimum wage

$$
\bar{w}^{S}=B+\frac{1}{2 c n^{S}}-\frac{t}{6\left(n^{S}\right)^{2}} .
$$

Because $\bar{w}^{S}>w^{S}\left(n^{S}\right)$, this level of the minimum wage leads indeed to $n^{S}$ firms entering the market who make profit $\pi^{S}\left(n^{S}\right)=F$. 